\title{
Periodically forced neural mass model: entrainment and complex behavior
}

\author{
Andreas Spiegler ${ }^{1,2^{*}}$, Thomas R Knösche ${ }^{1}$, Fatihcan M Atay ${ }^{3}$ \\ From Nineteenth Annual Computational Neuroscience Meeting: CNS*2010 \\ San Antonio, TX, USA. 24-30 July 2010
}

Neural mass models (NMM) provide a parsimonious, yet biophysically plausible, way to model mass action in the nervous system [1]. It has been demonstrated that, even in the absence of any time-variant input, they are capable of producing a number of biologically relevant behavior [2]. Moreover, by slowly traversing the parameter space, they can serve as generative models for ordered sequences of oscillatory regimes observed in EEG or MEG data [2]. In the brain, neural circuits are embedded in global networks and may experience high amplitude input from other areas. Such input is very often periodic. Here, we systematically investigate the behavior of a NMM of a cortical area, comprising three neural masses for pyramidal cells and inhibitory and excitatory interneurons, in response to periodic input, as a function of input amplitude and frequency.

In our previous work we studied the system with constant input [2]. Two mechanisms for oscillations could be identified: homoclinic and Hopf cycles. Here, we extend our study by considering periodic pulse-like input and systematically vary amplitude and frequency of the input for the widely used parameter set proposed by Jansen and Rit [1]. The input frequency ranges between $4 \mathrm{~Hz}$ and $19 \mathrm{~Hz}$ including the intrinsic frequency (correponding to the Hopf cycle), and the amplitude values are $1 / 3,2 / 3,1,4 / 3$ and $5 / 3$ of amplitude of the Hopf cycle in the unperturbed system. We study the phase space orbits and the time evolution of all variables. The largest Lyapunov exponents and the spectra of the time series are calculated. For studying the relationship of system input and response we compute the frequency-detuning curves, i.e., the frequency difference of response and input plotted against the input frequency.

For slight perturbation we found frequency entrainment meaning that the cortical area responds with the stimulus frequency instead of the intrinsic frequency. Away from the entrainment chaotic behavior could be observed,

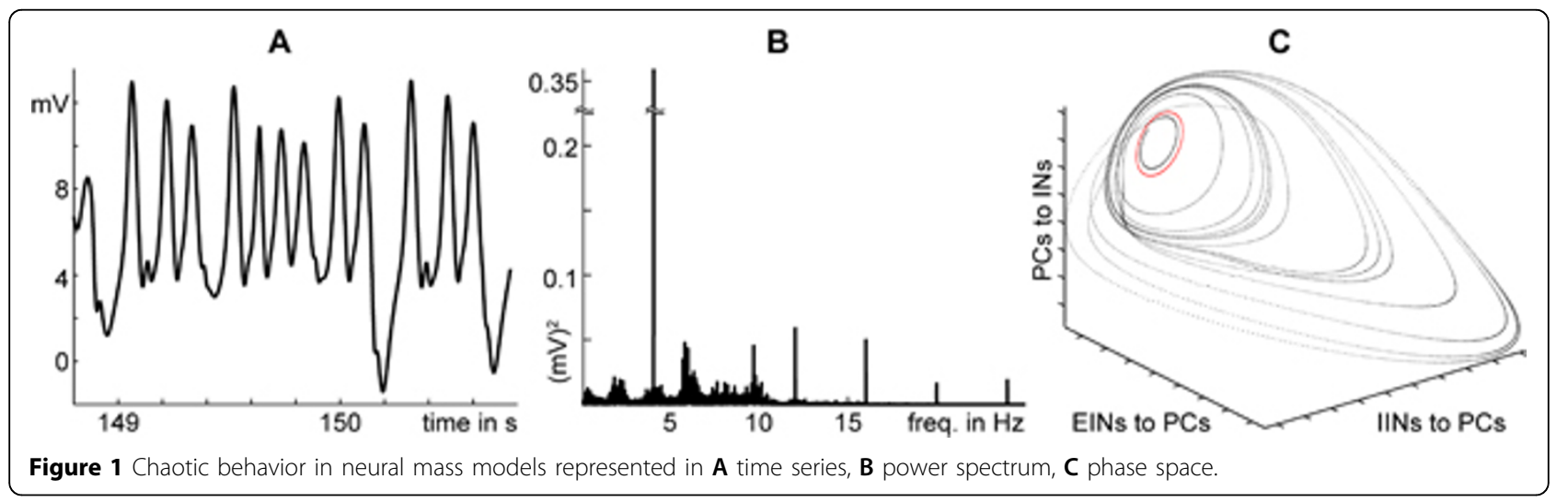

* Correspondence: spiegler@cbs.mpg.de

'Max Planck Institute for Human Cognitive and Brain Sciences, Leipzig,

04103, Germany 
indicated by broadband frequencies in the spectra and positive Lyapunov exponents, whose value in our example is 0.153 (see Figure 1). We also found quasi-periodic and multi-periodic behavior (high-dimensional tori), where the corresponding spectra are discrete with multiple frequency components.

\section{Conclusions}

For the first time we found complicated behavior like entrainment, chaos, quasi- and multi-periodicity in a neural mass model by using periodic input. Hence, this NMM may be capable of serving as a generative model for much more complex and diverse phenomena than previously thought.

\section{Author details}

${ }^{1}$ Max Planck Institute for Human Cognitive and Brain Sciences, Leipzig, 04103, Germany. ${ }^{2}$ Institute for Biomedical Engineering and Informatics, Technical University of IImenau, IImenau, 98693, Germany. ${ }^{3}$ Max Planck Institute for Mathematic in the Sciences, Leipzig, 04103, Germany.

Published: 20 July 2010

\section{References}

1. Jansen BH, Rit VG: Electroencephalogram and visual evoked potential generation in a mathematical model of coupled cortical columns. Biol Cybern 1995, 73:357-366.

2. Spiegler A, Kiebel SJ, Atay FM, Knösche TR: Bifurcation analysis of neural mass models: Impact of extrinsic inputs and dendritic time constants. Neurolmage 2010.

\section{doi:10.1186/1471-2202-11-S1-P7}

Cite this article as: Spiegler et al:: Periodically forced neural mass model: entrainment and complex behavior. BMC Neuroscience 2010 11(Suppl 1):P7.

\section{Submit your next manuscript to BioMed Central} and take full advantage of:

- Convenient online submission

- Thorough peer review

- No space constraints or color figure charges

- Immediate publication on acceptance

- Inclusion in PubMed, CAS, Scopus and Google Scholar

- Research which is freely available for redistribution

Submit your manuscript at www.biomedcentral.com/submit 